\title{
РЕЗУЛЬТИРУЮЩИЕ КОМПОНЕНТЫ РАЗВИТИЯ РЕГИОНАЛЬНЫХ СОЦИАЛЬНО-ЭКОНОМИЧЕСКИХ СИСТЕМ РОССИЙСКОЙ ФЕДЕРАЦИИ
}

\author{
(c) 2020 Авдуевская Екатерина Алексеевна \\ ассистент, Высшая инженерно-экономическая школа \\ Санкт-Петербургский политехнический университет Петра Великого, Россия, Санкт-Петербург \\ E-mail: avduevskaya_ea@spbstu.ru \\ (C) 2020 Карпенко Павел Алексеевич \\ Высшая инженерно-экономическая школа \\ Санкт-Петербургский политехнический университет Петра Великого, Россия, Санкт-Петербург
}

На сегодняшний день в отечественной литературе представлено большое разнообразие авторских методик оценки регионального социально-экономического развития регионов. Данные методики отвечают разнообразным целям, основаны на различных методах, в том числе математического и статистического анализа, а также включают в себя уникальные перечни результирующих показателей. В данной статье авторами проводится анализ отечественного опыта оценки регионального социально-экономического развития. Авторами рассматриваются цели и приоритеты используемых методик, а также проводится сравнительный анализ результирующих компонентов, используемых в рассматриваемых методиках. По результатам сравнительного анализа, авторами сделан вывод, что все методики характеризуются использованием широкого спектра показателей, которые охватывают все сферы развития, в том числе качество жизни, здравоохранение, образование, экономику, экологию и т.д. Однако наиболее популярным среди результирующих показателей уровня социально-экономического развития региона остается ВРП. По мнению авторов, в данной области еще остается место для дальнейших научных изысканий с целью нахождения оптимального набора результирующих показателей, характеризующих всестороннее развитие региональных социально-экономических систем.

Ключевые слова: региональные социально-экономические системы, социально-экономическое развитие региона, методики оценки развития регионов, интегральные показатели, валовый региональный продукт

\section{Введение}

Устойчивое развитие страны в первую очередь зависит от стабильного развития всех ее регионов. Для Российской Федерации выполнение данного положения осложнено, в первую очередь, наличием относительно других стран масштабных территорий, во-вторых, наличием диспропорции имеющихся материальных и нематериальных (в том числе человеческих) ресурсов. При планировании и реализации механизмов развития территорий важно учитывать данную диспропорцию, поэтому для каждого конкретного субъекта необходимо разрабатывать уникальные подходы и методы оценки регионального развития. Данная потребность обуславливает научный интерес среди российских исследователей в данной области, поэтому на сегодняшний день в отечественной литературе представлено большое разнообразие авторских методик оценки развития регионов как социально-экономических систем, различающихся не только применяемым методологическим аппаратом, но и обоснованием выбора результирующих показателей регионального развития [1]. Целью данной статьи является анализ методик оценки регионального социальноэкономического развития и эффективности регионального управления с позиции сравнения результирующих компонентов, используемых в рассматриваемых методиках.

\section{Основная часть}

Под развитием обычно понимают процесс перехода от одного состояния в другое, более совершенное [2]. Говоря про устойчивое развитие регионов, в первую очередь, понимается развитие в соответствии с требованием согласованности между социальными, экономическими и природно-экологическими факторами. На сегодняшний день отечественные авторы, в том числе базируясь на фундаментальных трудах 
зарубежных исследователей, предлагают различные авторские методики оценки развития региональных социально-экономических систем [3]. Разрабатываемые методики оценки регионального развития носят не только теоретический характер, но прикладной, с точки зрения использования их в планировании и реализации мер территориального развития. В целом, как отмечается в исследовании [4], методики оценки социально-экономического развития региона могут преследовать следующие цели и области применения:

- для определения степени нуждаемости регионов в дополнительном финансировании;

- для оценки степени межрегиональной дифференциации регионов;

- для целей устранения неравномерности в уровнях регионального социальноэкономического развития;

- для оценки эффективности управления социально-экономическим развитием региона;

- для целей анализа и прогнозирования социально-экономического развития региона.

Региональное социально-экономическое развитие напрямую зависит от решений и методов исполнительных органов власти региона, применяемых во исполнение текущих и стратегических задач. На сегодняшний день, регулирование деятельности региональных исполнительных органов власти с точки зрения законодательства осуществляется с помощью нормативно-правовых актов различных уровней, например, в Конституции Российской Федерации определены предметы ведения субъектов РФ. Важным документом, регулирующим деятельность аппарата регионального управления, является Федеральный закон от 06.10.1999 N 184-Ф3 (ред. от 13.07.2020) «Об общих принципах организации законодательных (представительных) и исполнительных органов государственной власти субъектов Российской Федерации» [5]. В статье 26.3.2 данного Федерального Закона № 184-ФЗ устанавливаются основные принципы проведения оценки эффективности деятельности органов исполнительной власти субъекта Российской Федерации, вместе с тем, наиболее интересными для целей настоящего исследования являются следующие законодательные акты, принятые во исполнение принципов, указанных в ФЗ [6,7]:

1) Указ Президента РФ от 25 апреля 2019 г. N 193 «Об оценке эффективности деятельности высших должностных лиц (руководителей выс- ших исполнительных органов государственной власти) субъектов Российской Федерации и деятельности органов исполнительной власти субъектов Российской Федерации», в котором устанавливается перечень показателей для оценки эффективности деятельности руководителей высших должностных лиц субъектов Российской Федерации и деятельности органов исполнительной власти субъектов Российской Федерации;

2) Постановление Правительства РФ от 17 июля 2019 г. N 915 «Об утверждении методик расчета показателей для оценки эффективности деятельности высших должностных лиц (руководителей высших исполнительных органов государственной власти) субъектов Российской Федерации и деятельности органов исполнительной власти субъектов Российской Федерации, а также о признании утратившими силу некоторых актов Правительства Российской Федерации»;

3) Постановление Правительства РФ от 29 ноября 2019 г. № 1537 «О поощрении субъектов Российской Федерации за достижение значений (уровней) показателей для оценки эффективности деятельности высших должностных лиц (руководителей высших исполнительных органов государственной власти) субъектов Российской Федерации и деятельности органов исполнительной власти субъектов Российской Федерации в 2019 году».

В соответствии с Указом Президента РФ № 193, в перечень результирующих показателей включены следующие показатели [6]:

1. «Уровень доверия к власти (Президенту Российской Федерации, высшим должностным лицам (руководителям высших исполнительных органов государственной власти) субъектов Российской Федерации).

2. Количество высокопроизводительных рабочих мест во внебюджетном секторе экономики.

3. Численность занятых в сфере малого и среднего предпринимательства, включая индивидуальных предпринимателей.

4. Производительность труда в базовых несырьевых отраслях экономики.

5. Уровень реальной среднемесячной заработной платы.

6. Объем инвестиций в основной капитал, за исключением инвестиций инфраструктурных монополий (федеральные проекты) и бюджет- 
ных ассигнований федерального бюджета.

7. Уровень бедности.

8. Ожидаемая продолжительность жизни при рождении.

9. Естественный прирост населения.

10. Количество семей, улучшивших жилищные условия.

11. Уровень доступности жилья.

12. Доля городов с благоприятной городской средой.

13. Качество окружающей среды.

14. Уровень образования.

15. Доля соответствующих нормативным требованиям автомобильных дорог регионального значения и автомобильных дорог в городских агломерациях с учетом загруженности».

На основании утвержденного перечня, методик расчета показателей, указанных в данном перечне, а также правил, установленных в Постановлении Правительства РФ от 29 ноября 2019 г. № 1537 осуществляется оценка эффективности деятельности регионального органа исполнительной власти, результаты которой являются обоснованием для распределения межбюджетных трансфертов из федерального бюджета субъектам Российской Федерации на дальнейшее развитие. Таким образом, используемые в перечне показатели можно считать результирующими компонентами развития региональной социально-экономической системы.

Как было отмечено ранее, отечественные авторы предлагают различные точки зрения на структуру используемых показателей при оценке уровня развития региональных социальноэкономических систем. В исследовании [8] приводятся результаты анализа методик оценки эффективности регионального развития, на основании которых авторы выделили два основных подхода, которые применяются отечественными исследователями. Первый подход, по классификации авторов, сводится к использованию универсального показателя - валовый региональный продукт (ВРП), который, в зависимости от целей и приоритетов исследования, может быть дополнен другими социальными или экономическими показателями. В этом случае, методики оценки регионального управления, могут быть основаны на использовании интегрального подхода [8]. Среди методик, основанных на использовании данного подхода можно выделить, например, методику А.Н.Гириной, в основе которой заложена оценка показателей, характеризующих развитие регионального производственного комплекса (в том числе ВРП, основные фонды и трудовые ресурсы), научной сферы региона и развития информационнокоммуникационной инфраструктуры экономики региона. А также методику, разработанную авторами Т.В.Погодиной и С.А.Бренчаговой [9]. В рамках разработанной ими методики результативность социально-экономического региона характеризуется такими показателями, как:

- валовый региональный продукт (ВРП);

- объем промышленной продукции;

- валовая продукция сельского хозяйства;

- объем работ по договорам строительного подряда;

- инвестиции в основной капитал;

- денежные доходы населения в среднем за месяц;

- розничный товарооборот.

Второй подход, который часто применяется отечественными авторами, сводится к оценке эффективности регионального управления через соответствие результатов работы установленному (эталонному) уровню. В этом случае, авторы используют такие показатели, как валовый внутренний продукт (ВВП) на душу населения или, как и в первом подходе, авторы прибегают к использованию интегральных индексов (например, индексы развития человеческого капитала) [8].

Интересным с научным точки зрения является подход оценки развития регионов, описанный в исследовании О.К.Слинковой. Автор исследования указывает, что конечным результатом развития регионов, в первую очередь, является повышения благосостояния людей, проживающих в этом регионе [2]. В соответствии с этим положением, результирующими показателями социально-экономического развития региона являются индикаторы, характеризующие уровень и качество жизни населения. Под уровнем жизни понимается количественная характеристика образа жизни, при оценке которого часто используют статистические данные. Уровень жизни характеризуется совокупностью показателей, которые характеризуют уровень, структуру и возможности потребления населения. В свою очередь, качество жизни - это качественная характеристика образа жизни населения, которая в отличие от уровня жизни, охватывает разнообразные сферы существования и деятельности, в том числе, жизненного потенциала и ус- 
ловий обитания (жизнедеятельности). В отличие от уровня жизни, оценка качества жизни населения сопряжена с рядом трудностей, в том числе, со сложностью перевода качественных характеристик в количественные показатели. Также при использовании подхода, базирующегося на сведение качественных характеристик в интегральный показатель, наблюдается сложность в определении значимости (весов) некоторых элементов, а отсутствие единого подхода к определению элементов, входящих в данный показатель, приводит к несогласованности получаемых результатов и сложности их интерпретации.

На рисунке 1 представлена классификация показателей, характеризующих уровень и качества жизни населения.

К исследованиям, в которых в качестве главного индикатора социально-экономического развития региона используются показатели, характеризующие уровень и качество жизни населения, можно также отнести труды Т.Н. Мацкевича и М.А. Исакина. В исследовании Т.Н.Мацкевича центральное место в системе показателей, оценивающих уровень социальноэкономического развития региона, занимает комплексный показатель - индекс развития человеческого потенциала, а в трудах М.А.Исакина - ВРП (ВВП), индекс физического качества жизни (средневзвешенное индексов грамотно- сти, детской смертности и ожидаемой продолжительности жизни в возрасте 1 года) [10].

Как уже отмечалось ранее, разрабатываемые методики могут обладать различным целевым характером. Так, например, интересным является подход, описанный в работе авторов Реутова В.Е. и ХомицкойД.А. [11]. В данном исследовании вопрос результирующих показателей развития региональных социальноэкономических систем рассматривается в контексте разработки методики выявления и оценки социально-экономических диспропорций регионального развития [11]. В рамках разработанной методики авторами предлагается алгоритм выявления диспропорций социальноэкономического регионального развития через ряд систем количественных показателей, в том числе, характеризующих диспропорциональность социально-экономического развития по уровню развития регионов. Рассматриваемая авторами исследования система показателей делится на 3 блока [11] (см. таблицу 1).

Данная методика отличается тем, что включает в себя достаточно большой перечень результирующих показателей, характеризующих развитие регионов как социально-экономических систем. Также следует отметить, что данный перечень отвечает принципам устойчивого развития регионов, так как учитывает, как социально-

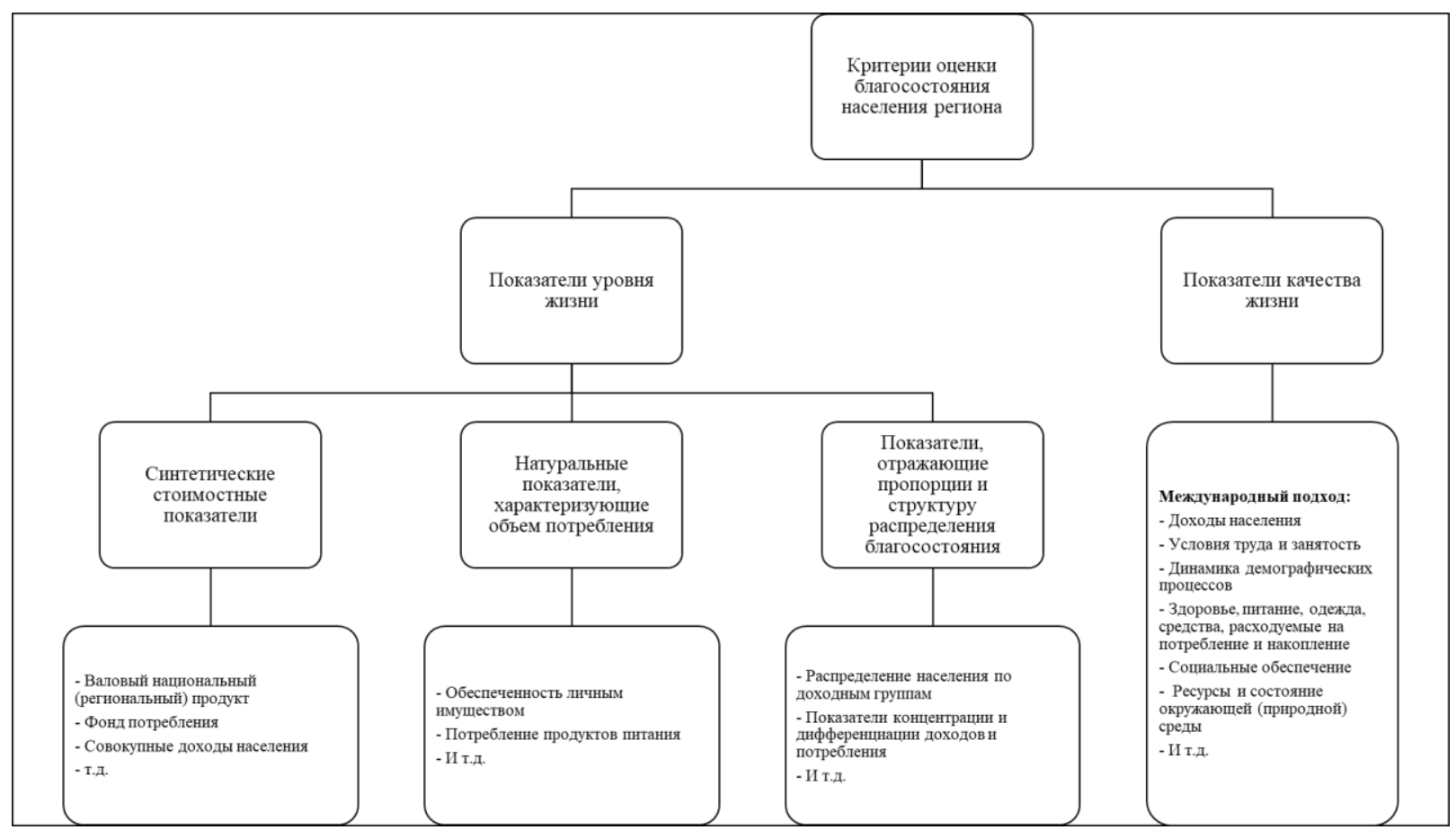

Рисунок 1. Классификация показателей, характеризующих уровень и качество жизни населения. 
Таблица 1. Количественные показатели, характеризующие диспропорциональность социальноэкономического развития по уровню развития регионов по методике Реутова В.Е. и Хомицкой Д.А. [11]

\begin{tabular}{|c|c|c|}
\hline 1. Экономический блок & 2. Социальный блок & 3. Экологический блок \\
\hline $\begin{array}{l}\text { 1.1. валовый региональный про- } \\
\text { дукт на душу населении, руб.; } \\
\text { 1.2. объем иностранных инвести- } \\
\text { ций на душу населения, у.е.; } \\
\text { 1.3. инвестиции в основной капи- } \\
\text { тал на душу населения, руб.; } \\
\text { 1.4. экспорт товаров и услуг в } \\
\text { расчете на одного человека, долл. } \\
\text { США; } \\
\text { 1.5. количество малых предприя- } \\
\text { тий на } 10 \text { тыс. человек населения, } \\
\text { ед.; } \\
\text { 1.6. удельный вес промышленных } \\
\text { предприятий, внедряющих инно- } \\
\text { вации,\%; } \\
\text { 1.7. доля трансферов в доходах } \\
\text { местных бюджетов,\%. }\end{array}$ & $\begin{array}{l}\text { 2.1. коэффициент демографиче- } \\
\text { ской нагрузки (количество пенсио- } \\
\text { неров на } 1000 \text { человек населения); } \\
\text { 2.2. количество лиц, пострадав- } \\
\text { ших от преступлений (на } 10 \text { тыс. } \\
\text { населения); } \\
\text { 2.3. уровень безработицы по мето- } \\
\text { дологии МОт,\%; } \\
\text { 2.4. количество предприятий } \\
\text { розничной торговли (на } 10 \text { тыс. } \\
\text { населения); } \\
\text { 2.5. количество предприятий } \\
\text { ресторанного хозяйства (на } 10 \text { тыс. } \\
\text { населения); } \\
\text { 2.6. обеспеченность населения } \\
\text { амбулаторно-поликлиническими } \\
\text { учреждениями (на } 10 \text { тыс. населе- } \\
\text { ния); } \\
\text { 2.7. уровень охвата детей дошколь- } \\
\text { ными учреждениями,\% к коли- } \\
\text { честву детей соответствующего } \\
\text { возраста; } \\
\text { 2.8. обеспеченность населения жи- } \\
\text { льем, м2 общей площади на одного } \\
\text { жителя; } \\
\text { 2.9. доходы населения на одного } \\
\text { человека, руб.; } \\
\text { 2.10. среднемесячная заработная } \\
\text { плата наемных работников; } \\
\text { 2.11. депозитные средства физиче-- } \\
\text { ских лиц на одного человека, руб.; } \\
\text { 2.12. коэффициент смертности } \\
\text { детей в возрасте до } 1 \text { года по реги- } \\
\text { онам на 1000 родившихся живыми, } \\
\text { чел. }\end{array}$ & $\begin{array}{l}\text { 3.1. забор воды из природных во- } \\
\text { дных объектов для использования } \\
\text { в расчете на одного человека, м3; } \\
\text { 3.1. выбросы вредных веществ в } \\
\text { атмосферный воздух в расчете на } \\
\text { одного человека, кг; } \\
\text { 3.3. выбросы вредных веществ в } \\
\text { атмосферный воздух в расчете на } \\
\text { км, т; } \\
\text { 3.4. образование отходов I-III } \\
\text { классов опасности в расчете на } \\
\text { одного человека, кг». }\end{array}$ \\
\hline
\end{tabular}

экономические, так и природно-экологические компоненты.

В группу методик, нацеленных на оценку регионального социально-экономического развития с точки зрения имеющейся диспропорции или количественной оценки степени отличия субъектов друг от друга, также можно отнести методику, предложенную автором В.П.Самариной. По мнению автора, уровень неравномерности социально-экономического развития регионов можно оценить через такие индикаторы, как:

- «валовый региональный продукт;

- объем внешнеторгового оборота на душу населения;

- процентное соотношение среднедушевых доходов и среднедушевого прожиточного минимума;

- процентная доля населения с доходами выше прожиточного минимума» $[10,12]$.

В целом, по результатам сравнительного анализа методик оценки регионального социальноэкономического развития можно отметить, что все методики характеризуются использованием широкого спектра показателей, которые охватывают все сферы развития, в том числе качество жизни, образование, здравоохранение, экономику, экологию и т.д. Однако сегодня наиболее популярными среди результирующих показателей уровня социально-экономического развития региона остаются экономические показатели и в большей степени - валовый региональный продукт. На взгляд авторов, в данной области еще остается место для дальнейших научных изысканий с целью нахождения оптимального набора результирующих показателей, характеризующих всестороннее развитие региональных социально-экономических систем. 


\section{Библиографический список}

1. Родионов Д.Г., Баранова И. В., Насрутдинов М.Н. Формирование модели интерферирования показателей социального потенциала региона // Российский экономический интернет-журнал. Открытое акционерное общество Институт исследования товародвижения и ..., 2019. № 4. С. 119.

2. Слинкова О.К. Уровень и качество жизни населения как результирующие показатели социальноэкономического развития регионов // Вестник Иркутского государственного технического университета. Федеральное государственное бюджетное образовательное учреждение высшего ..., 2012. № 9 (68).

3. Родионов Д.Г., Баранова И. В., Насрутдинов М.Н. Идентификация ключевых медиаторов развития социального потенциала региона // Российский экономический интернет-журнал. Открытое акционерное общество Институт исследования товародвижения и ..., 2019. № 3. С. 69.

4. Гирина А.Н. Методика оценки социально-экономического развития региона // Вестник Оренбургского государственного университета. Федеральное государственное бюджетное образовательное учреждение высшего ..., 2013. № 8 (157).

5. Федеральный закон от 06.10.1999 N 184-Ф3 (ред. от 13.07.2020) «Об общих принципах организации законодательных (представительных) и исполнительных органов государственной власти субъектов Российской Федерации».

6. Указ Президента РФ от 25 апреля 2019 г. N 193 «Об оценке эффективности деятельности высших должностных лиц (руководителей высших исполнительных органов государственной власти) субъектов Российской Федерации и деятельности органов исполнительной власти.

7. Постановление Правительства РФ от 17 июля 2019 г. N 915 «Об утверждении методик расчета показателей для оценки эффективности деятельности высших должностных лиц (руководителей высших исполнительных органов государственной власти) субъектов Российской Ф.

8. Федорова Е.А., Черникова Л.И., Мусиенко С. О. Оценка эффективности регионального управления // Экономика региона. Федеральное государственное бюджетное учреждение науки «Институт экономики ..., 2019. T. 15, № 2 .

9. Погодина Т.В., Бренчагова С. А. Анализ и интегральная оценка социально-экономического развития регионов Приволжского федерального округа // Региональная экономика теория и практика. Общество с ограниченной ответственностью «Издательский дом ФИНАНСЫ и КРЕДИТ», 2005. № 12.

10. Меньщикова В.И. Стратегия социально-экономического развития в системе управления регионом // Вестник Тамбовского университета. Серия: Гуманитарные науки. Федеральное государственное бюджетное образовательное учреждение высшего ..., 2009. № 6.

11. Реутов B.Е., Хомицкая Д. А. Методика выявления социально-экономических диспропорций регионального развития // Экономика: вчера, сегодня, завтра. Общество с ограниченной ответственностью Аналитика Родис, 2017. Т. 7, № 2А. С. 145.

12. Самарина В.П. Особенности оценки неравномерности социально-экономического развития регионов // Проблемы современной экономики. Общество с ограниченной ответственностью» Научнопроизводственная компания ..., 2008. № 1. С. 300-303. 